\title{
Research of Embedded System Experimental Teaching of IOT Engineering Major
}

\author{
Yonghui Jiang \\ School of Information Science and Technology, Hainan Normal University, Haikou, China \\ philjyh@163.com
}

Keywords: IOT engineering; Embedded system; Experimental teaching

\begin{abstract}
As the most pressing need of application-oriented talents in IOT Engineering major, and according to the CDIO education idea, combining the content and characteristics of the embedded system course, this paper puts forward the experimental scheme design about the layering embedded system course, and puts it into practice as the form of projected to enhance the IOT students' practice and innovation ability about embedded system, and lay a good foundation for their career development.
\end{abstract}

\section{Introduction}

IOT is one of the strategic emerging industries in "12th Five-Year plan", which is an important impetus to accelerate the transformation of economic development in China. To meet the urgent needs to develop the strategic emerging industries about high-quality talents of IOT technology, there are 382 colleges and universities who have set up the IOT Engineering major till 2017. It is not only a great impression that our nation and government develop the IOT industry, but also a great move that our nation make a timely reflection on talent cultivation model.

Embedded system is one of the key technologies of IOT. It is the only things to things source, things to things method and things to things interface of IOT application. It is also the front-end platform to realize the perceive and control, the device node to realize the ubiquitous network, the user interface to realize service[1]. Therefore, embedded system course is very important in IOT Engineering courses. Many colleges and universities have taken the embedded system course as the core professional course.

The application-oriented talent target of IOT technology highly demands the practical ability of embedded system. However, the content of embedded system is extensive and comprehensive, and the basic requirements of software and hardware are higher, which brings a great challenge to practice teaching about embedded system course. Therefore, it is very meaningful to carry out the teaching research of embedded system course practice.

\section{The Existing Problems about Embedded System Practical Courses}

The application of embedded system is the emphasis, and the technique of computer application is basis, hardware and software can be cut out. There is a pretty strict limit of reliability, cost, volume and energy-consuming [2]. The current microelectronics technology and its development makes the embedded CPU chip with a stronger processing ability and more basic interface, which has widely used in industrial control, information appliances, communications equipment, medical equipment, intelligent instrumentation and other fields [3-5]. Embedded system has wider range of knowledge, higher comprehensive and stronger practical. Therefore, the embedded system of practical teaching requirements are higher.

Currently, there are following problems existing when the IOT Engineering major offers the practice teaching courses of embedded systems.

Inadequate Experimental Hours. Embedded system is a highly practical course, which requires a lot of practice to assist learning, so that the student can apply the theory to practice systematically and creatively. But now, there are still many colleges and universities put too much 
emphasis on theoretical teaching while setting up this course, causing inadequate arrangements for experimental time. It seriously affect the quality of application-oriented talent of IOT technology.

Simplification Experimental Way and Lack of Mature Embedded System Experimental Program Which Faces to IOT. A a new major, IOT Engineering is lagging behind in practice teaching construction. In embedded system experimental courses, many colleges and universities mainly take different manufacturers' experimental equipment and use its matching experimental program. But those experimental equipment manufacturers are lack of teaching experience. All experimental programs they designed require the student to verify the theory what they learned. And those programs are lack of comprehensive and innovative. Those experimental projects aimed at practical application, is not only difficult to improve the student's innovation, but also makes the student's comprehensive ability can not meet the social needs. Students who carried out the experiment are mostly mechanical accordance with the experimental instructions. There is no principle that can allow the students to think independently, which makes a lot of students to lose the learning interest in this mechanization experiment.

\section{The Embedded System Experimental Design for IOT}

According to the present disadvantage of embedded system experimental teaching about IOT Engineering, this paper divides the embedded system experimental content into basic experiment, designed experiment, comprehensive experiment and innovative experiment. The difficulty of those four levels is increasing in turn, so that the student can qualify solid theoretical basis, skilled ability to software development and rich practical experience. The experimental scheme designed in this paper is shown in Table 1.

Table 1 Embedded System Experimental Scheme

\begin{tabular}{|c|c|c|}
\hline $\begin{array}{c}\text { Experiment } \\
\text { Types }\end{array}$ & Experiment Projects & Organization Form \\
\hline $\begin{array}{c}\text { Basic } \\
\text { experiment }\end{array}$ & $\begin{array}{l}\text { 1. Construction and use of embedded system } \\
\text { development environment } \\
\text { 2. ARM assembly language and C language } \\
\text { programmed experiment } \\
\text { 3. Basic serial experiments (serial, clock, } \\
\text { interrupt, etc.) }\end{array}$ & $\begin{array}{c}\text { Verify in experimental } \\
\text { courses }\end{array}$ \\
\hline $\begin{array}{l}\text { Designed } \\
\text { experiment }\end{array}$ & $\begin{array}{c}\text { 1. BootLoader experiment } \\
\text { 2. Linux transplant experiment } \\
\text { 3.Linux multithreading programmed experiment } \\
\text { 4. Linux driver experiment } \\
\text { 5.Socket communication experiment under } \\
\text { Linux } \\
\text { 6.Web server establishment and dynamic Web } \\
\text { experiment under Linux } \\
\text { 7. Linux graphical user interface experiment }\end{array}$ & $\begin{array}{l}\text { Experimental courses } \\
\text { and process in open } \\
\text { experiment time }\end{array}$ \\
\hline $\begin{array}{c}\text { Comprehensive } \\
\text { experiment }\end{array}$ & $\begin{array}{l}\text { 1. Embedded IOT gateway } \\
\text { 2.Embedded greenhouses environmental } \\
\text { information collection system }\end{array}$ & $\begin{array}{l}\text { The experimental } \\
\text { project is optional and } \\
\text { be processed in open } \\
\text { experimental time, as } \\
\text { the form of an } \\
\text { experimental group }\end{array}$ \\
\hline
\end{tabular}

The basic experiment is to enable the student to understand and verify the theory what they learned. Through those experiments in this level, the student can be familiar with embedded hardware and software development environment, and can be skilled in using various development 
software and also master basic hardware and software debugging methods. During the experiment, the student should be guided to think about the relationship between experimental principle and phenomenon, show the experiment's guidance function to what the theory they learned and overcome the drawbacks to mechanical experiment result.

Designed experiment refers that the experiment can be completed independently by students based on the designed project indicators and experimental block diagram, after the student can master a certain degree of embedded system theory and development skills. Through those experiments in this level, students can be developed to deal with some more complex problems. During the experiment, the teacher can take the practical IOT applications scene as experiment target. For example, the IOT gateway can be used as an application scenario and the students can complete the Sochet communication experiments under Linux to stimulate their interest in learning.

The comprehensive experiment requires the student to complete the experiment when using the embedded system and other relevant professional knowledge of IOT, such as to complete the embedded IOT gateway and complete the embedded greenhouses environmental information collection system. The experiment requires students to do in open experimental time as the form of groups and mainly to enable students to master the development process and method of embedded system, and develop their team spirit.

The innovative experiment is completed mainly as the form that the teacher guide their students to work as a team. By guiding, the student team participate in subject competitions and research projects. And also, the teacher will guide their students to focus on a certain important technology or hot issues about IOT application and stimulate students' innovative thinking and consciousness, so that the student can master the method of problem thinking and problem-solving, and improve their ability to innovative practice.

\section{Projected Experiment Implementation based CDIO}

CDIO engineering education model is a new educational model of engineering education reform, which was funded by the Massachusetts Institute of Technology, the Royal Swedish Institute of Technology and other four universities in Wallenberg and founded in 2004 [6-10].

As a product carrier of whole life process, which is from concept, research, development, operation, abandoned and re-use, the student can take the study way of initiative, practical and organic connect between different courses. It is what happened in accordance with trends. Aiming at the practical characteristics of embedded system and need for application-oriented talent, combining with the CDIO concept, this paper carry out the projected embedded experimental teaching .

CDIO model emphasizes that the student should learn by themselves, and is committed to problem thinking and solving. To use projected experimental teaching, students' learning interest can be stimulated. The teacher-based negative learning model "learning from listening" can transfer to a learning-oriented active learning model "learning from doing". This paper takes the "Embedded IOT Gateway" as an example, to state the projected implementation process.

When developing an embedded system experiment, the teacher uses the project-driven method to demonstrate the effect of embedded IOT gateway and then organize the student to discuss the system functional requirements and technology that required by system . By doing this, the students' interest can be stimulated. After that, the embedded IOT gateway system is decomposed into 10 different experiments, according to the experimental objectives based on achieving a certain function of the IOT Gateway module. Those 10 different experiments are construction and use of embedded system development environment, ARM assembly language and C language programmed experiment, Serial Communication experiment, BootLoader experiment, Linux transplant experiment, Linux multithreading programmed experiment, Linux driver experiment, Socket communication experiment under Linux, Web server establishment and dynamic Web experiment under Linux, QT graphical interface design, which are corresponding to the basic experiment and designed experiment in Table 1 and covers the whole process of embedded project development. 


\section{Summary}

This paper proposes a hierarchical experimental scheme for embedded system of the IOT, and decomposes an actual Internet of Thing application project into an experimental project according to CDIO concept. In the embedded experimental scheme, the students can complete a Internet of Thing application system after the experiment. Through this project of experimental implementation, it can enhance the student's practical ability and innovative ability, to ensure the cultivation needs for application-oriented talent.

\section{Acknowledgements}

This work is supported by an Education Teaching and Research Achievement of Hainan Province (QJY13516014) which presides by Junkuo Cao.

\section{Reference}

[1] He L. Embedded System for IOT[J]. Microcontrollers \& Embedded Systems, 2010, 10(7):538.

[2] Xu Yinghui, Ma Zhongmei, et al. ARM9 embedded system design based Linux[M].Beijing: BUAA Press. 2009

[3] Sun S M, Liu X P, Zheng Q M, et al. Exploration on Experimental Teaching of Embedded System of Computer Specialty[J]. Research \& Exploration in Laboratory, 2009.

[4] Liu L, Yang X H, Jia-Yu M A. The Embedded System Training Reform Based on the Three-dimensional Model[J]. Computer Education, 2010.

[5] Han D, Zhang L, Shao W. Discussion on embedded system practice teaching of computer engineering professional direction[J]. Experimental Technology \& Management, 2010.

[6] Hu R. Research of Embedded System Course Teaching Model Based on CDIO[J]. Science Education Article Collects, 2014.

[7] Jian-Qiang L I, Wang Z Q, Xue L P. Research of Embedded System Teaching Based on CDIO Mode[J]. Computer Education, 2010.

[8] Liang Y E, Wan S M, Computer D O. Research on the Teaching Model of Embedded System Theory and Application Curriculum Based on CDIO[J]. Modern Computer, 2013.

[9] Chen R, Jiang P, Zhou G. Research and Practice of Embedded System based on CDIO Mode[J]. China Educational Technology \& Equipment, 2013.

[10] Yin J, Zhang M, Wan J. Study on the Reform of Practice Teaching of Embedded System Based on Combination of Competitions and Teaching[J]. Computer Education, 2011. 